\title{
TAKING UP THE INDEPENDENT LIVING CHALLENGES OF OUR TIMES
}

Volume 23 of the Journal of Child and Youth Care Work takes up the challenges of independent living. This special issue is a collaborative venture between the Association for Child and Youth Care Practice (ACYCP) and the National Staff Development and Training Association (NSDTA), affiliate of the American Public Human Services Association. The NSDTA and the ACYCP are kindred spirits in our commitment to use practice-based research and competencies to break new ground for the field and to ensure that training transfers to high quality practice.

Looking back and looking forward are thought pieces from past editors Varda Mann-Feder and Mark Krueger. Mann-Feder recently conducted extensive practice research on the developmental needs of the large number of youth who are aging out of care. Krueger, at the Youth Work Learning Center, has long been on the forefront of independent living and permanency planning, with innovative practice strategies generated by the workers together with the youth. The Youth Work Learning Center is a high power unit of a university, but for many years it directly operated its own independent living home for the purposes of learning. From The University of Oklahoma National Resource Center for Youth Services, we bring an article from Dorothy Ansell, who continues to pioneer the field of independent living and permanency through the seminal work of the Ansell-Casey Life Skills Assessment and Life Skills Guide, which has become an essential text and tool for our field.

To demonstrate the latest work in independent living skill training, we have arranged to share with you nine articles reprinted in cooperation with Training and Development in Human Services, the journal of the National Staff Development and Training Association (NSDTA). Among these articles are a range of program proposals submitted for actual implementation that give the reader an opportunity to explore opportunities and techniques available for the training of independent living curriculum. Professional work done in ten states assesses preparation and planning for independent living, explores how to plan effectively and achieve training outcomes, and designs successful techniques for evidence-based supervision and team based-training. Dale Curry and Andrew Schneider-Muñoz add to the lessons learned from each of the independent living curriculum by providing us with an examination of strategies to maximize the transfer-of-learning specifically for independent living training initiatives.

Rounding out this volume we move from curriculum to practice. John Korsmo provides us with his exploration of youth worker acquisition of professional knowledge and skill while Ken Harland and Tony Morgan, from the University of Ulster, take an in depth look at youth work and its contribution to life learning. Finally, with an eye to the future, editor Andy Schneider-Muñoz teams with Matthew Fasano, in identifying current trends in youth work identified by leaders in the field of youth development. 
On behalf of the Association for Child and Youth Care Practice, the editors of the Journal of Child and Youth Care Work (Andrew J. Schneider-Muñoz, Dale Curry, and Jean Carpenter-Williams), and the publisher, The University of Oklahoma OUTREACH National Resource Center forYouth Services, we would like to recognize the hard work and expertise of Anita Barbee and Becky Antle (guest editors of the Training and Development in Human Services issue) from the University of Louisville, personnel from the Center for Human Services, University of California, Davis who provided the copy editing, and personnel from Children and Family Training, Office of Children, Youth, and Families, Colorado who assisted with printing and distribution of the publication. We are grateful to the authors who were willing to share their findings and lessons learned from each of the independent living training grants and the U.S. Department of Health and Human Services, Administration for Children, Youth, and Families, Children's Bureau who provided funding. We hope this joint publication initiative is the first of many future collaborative activities shared by these two important professional associations that are comprised of highly dedicated individuals who promote the well-being of individuals and families in a variety of practice settings.

Andrew J. Schneider-Muñoz, EdD, CYC-P

University of Pittsburgh

Editor

Dale Curry, PhD, CYC-P

Kent State University

Coeditor

Jean Carpenter-Williams, MS, CYC-P

The University of Oklahoma OUTREACH

National Resource Center for Youth Services

President, Association for Child and Youth Care Practice 